\title{
AIP hamberdyis
}

\section{Structural and optical investigation of non-polar (1-100) GaN grown by the ammonothermal method}

D. Gogova, P. P. Petrov, M. Buegler, M. R. Wagner, C. Nenstiel, G. Callsen, M. Schmidbauer, R. Kucharski, M. Zajac, R. Dwilinski, M. R. Phillips, A. Hoffmann, and R. Fornari

Citation: Journal of Applied Physics 113, 203513 (2013); doi: 10.1063/1.4807581

View online: http://dx.doi.org/10.1063/1.4807581

View Table of Contents: http://scitation.aip.org/content/aip/journal/jap/113/20?ver=pdfcov

Published by the AIP Publishing

\section{Articles you may be interested in}

Nonpolar GaN substrates grown by ammonothermal method

Appl. Phys. Lett. 95, 131119 (2009); 10.1063/1.3227893

Impacts of dislocation bending and impurity incorporation on the local cathodoluminescence spectra of GaN grown by ammonothermal method

Appl. Phys. Lett. 91, 251911 (2007); 10.1063/1.2825471

Optical and structural microanalysis of GaN grown on SiN submonolayers

J. Appl. Phys. 99, 123518 (2006); 10.1063/1.2150589

Long carrier lifetimes in GaN epitaxial layers grown using TiN porous network templates

Appl. Phys. Lett. 86, 232106 (2005); 10.1063/1.1944903

Effect of dislocations on luminescence properties of silicon-doped $\mathrm{GaN}$ grown by metalorganic chemical vapor deposition method

J. Vac. Sci. Technol. B 22, 624 (2004); 10.1116/1.1667509

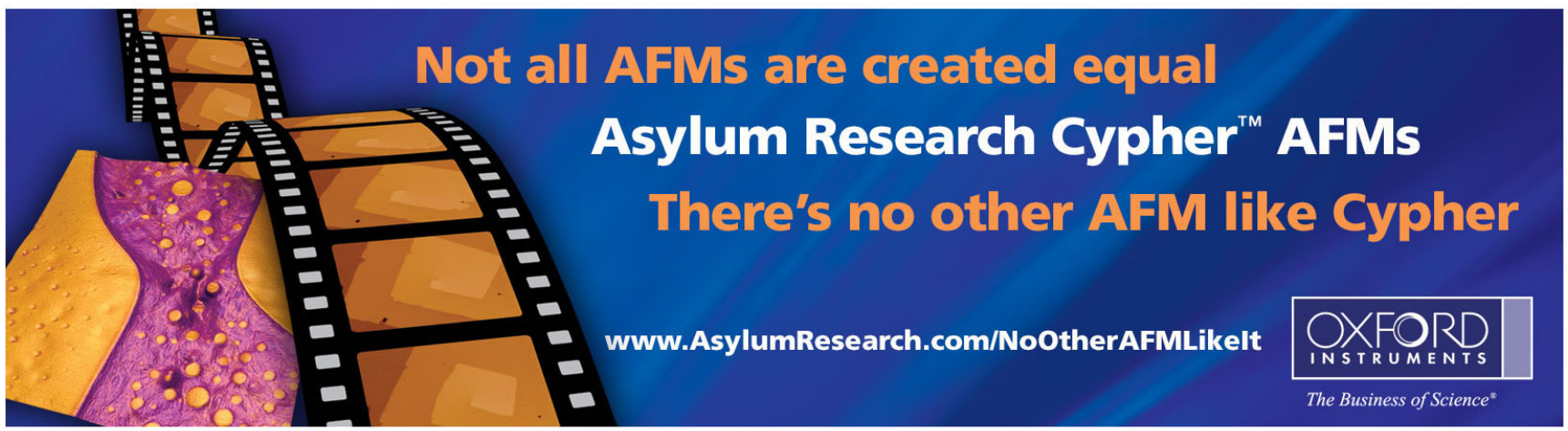




\title{
Structural and optical investigation of non-polar (1-100) GaN grown by the ammonothermal method
}

\author{
D. Gogova, ${ }^{1, a)}$ P. P. Petrov, ${ }^{1}$ M. Buegler, ${ }^{2}$ M. R. Wagner, ${ }^{2,3}$ C. Nenstiel,,${ }^{2,4}$ G. Callsen, ${ }^{2}$ \\ M. Schmidbauer, ${ }^{1}$ R. Kucharski, ${ }^{5}$ M. Zajac, ${ }^{5}$ R. Dwilinski, ${ }^{5}$ M. R. Phillips, ${ }^{4}$ A. Hoffmann, ${ }^{2}$ \\ and R. Fornari ${ }^{1}$ \\ ${ }^{1}$ Leibniz Institute for Crystal Growth, Max-Born-Str. 2, 12489 Berlin, Germany \\ ${ }^{2}$ Institut für Festkörperphysik, Technische Universität Berlin, Hardenbergstrasse 36, 10623 Berlin, Germany \\ ${ }^{3}$ Catalan Institute of Nanotechnology, 08193 Bellaterra (Barcelona), Spain \\ ${ }^{4}$ Department of Physics and Advanced Materials, UT Sydney, P.O. Box 123, Broadway, NSW 2007, Australia \\ ${ }^{5}$ Ammono S.A., 2/31 Czerwonego Krzyza Str., 00-377 Warsaw, Poland
}

(Received 4 April 2013; accepted 8 May 2013; published online 29 May 2013)

\begin{abstract}
We studied the structural and optical properties of state-of-the-art non-polar bulk GaN grown by the ammonothermal method. The investigated samples have an extremely low dislocation density (DD) of less than $5 \times 10^{4} \mathrm{~cm}^{-2}$, which results in very narrow high-resolution $\mathrm{x}$-ray rocking curves. The $a$ and $c$ lattice parameters of these stress-free GaN samples were precisely determined by using an x-ray diffraction technique based on the modified Bond method. The obtained values are compared to the lattice parameters of free-standing GaN from different methods and sources. The observed differences are discussed in terms of free-electron concentrations, point defects, and DD. Micro Raman spectroscopy revealed a very narrow phonon linewidth and negligible built-in strain in accordance with the high-resolution x-ray diffraction data. The optical transitions were investigated by cathodoluminescence measurements. The analysis of the experimental data clearly demonstrates the excellent crystalline perfection of ammonothermal GaN material and its potential for fabrication of non-polar substrates for homoepitaxial growth of $\mathrm{GaN}$ based device structures. @ 2013 AIP Publishing LLC. [http://dx.doi.org/10.1063/1.4807581]
\end{abstract}

\section{INTRODUCTION}

There is currently a great demand in the computer and telecommunication industries as well as in multimedia applications for multicolor light emitting displays as well as for high data-storage capacities in communication and recording systems. The III-nitrides are highly suitable for such applications due to their unique electronic and optical properties. Efficient short-wavelength laser diodes (LDs) emitting in the blue and ultraviolet regions have already been fabricated on the basis of III-nitrides and will be employed to achieve high-storage capacities for the next generation of multimedia systems. The future of full-color flat panel displays, green lasers, and optical communication is expected to largely depend on III-nitrides components. ${ }^{1,2}$

A crucial prerequisite for the effective employment of III-nitrides in device applications is the availability of highquality crystals with low concentrations of electrically and optically active defects. Heteroepitaxially grown GaN crystals usually suffer from considerable strain and high dislocation density (DD) $\left(10^{7}-10^{9} \mathrm{~cm}^{-2}\right)$ due to thermal and lattice mismatch with all known hetero-substrates. Such high DDs, however, constitute a serious limitation for the electron mobility and the efficiency of radiative recombinations, and may reduce device performance and operating lifetime. A decrease of the DD in the $10^{7} \mathrm{~cm}^{-2}$ range can be achieved by sophisticated techniques such as epitaxial lateral

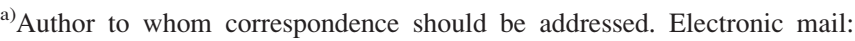
daniela.gogova@ikz-berlin.de
}

overgrowth (ELO) ${ }^{3,4}$ and pendeoepitaxy, ${ }^{5}$ which have been developed in the last decade. In order to improve the device performance and increase its lifetime, a further reduction of the DD is desirable. This can in principle be achieved by homoepitaxial growth of GaN, supposed that cost-effective GaN substrates with very low dislocation density are available. Furthermore, the availability of GaN substrates will eliminate the need for buffer layers in the growth of device structures and will provide significant advantages like vertical conduction, heat dissipation, and cleavability.

High-quality bulk GaN is therefore needed as substrate material to promote large-scale production of different electronic and optoelectronic devices with a high yield from the total wafer area. During the last ten years, the nitride community has paid special attention to the development of bulk crystal growth methods. ${ }^{6,7}$ Bulk growth of GaN single crystals has been attempted by using several techniques, such as the high-pressure solution growth (HPSG) method, ${ }^{10}$ the ammonothermal method, the sodium flux method, ${ }^{8,9}$ and halide vapor phase epitaxy (HVPE) ${ }^{11-14}$ Crystal platelets with superior crystalline quality (DD in the order of $10^{2} \mathrm{~cm}^{-2}$ ) have been prepared using HPSG but their maximum size of roughly $1 \mathrm{~cm}^{2}$ hinders the mass application. ${ }^{10}$

The quasi-bulk HVPE method has reached a DD limit of $10^{6} \mathrm{~cm}^{-2} \cdot{ }^{11-14}$ In comparison, state-of-the-art ammonothermal GaN exhibits DDs down to $10^{3}-10^{4} \mathrm{~cm}^{-1}$ for $2 \mathrm{in}$. wafers. ${ }^{15}$ Another advantage of ammonothermal GaN consists in the very large curvature radius of more than $100 \mathrm{~m}$, compared to about $10 \mathrm{~m}$ for HVPE GaN. ${ }^{11}$ This is the lowest curvature ever reported in the literature for $\mathrm{GaN}$ wafers and 
opens new possibilities for fabrication of III-N devices of superior quality.

The device technology developed on non-polar GaN overcomes many of the fundamental limitations of those based on the conventional c-plane GaN such as the constraints of device performance caused by quantum confined Stark effect due to strong internal piezoelectric field. ${ }^{16}$ Nonpolar $\mathrm{GaN}$ offers the potential for improved electrical efficiency, reduced electrical resistance, elimination of color shifting of light-emitting diodes (LEDs) and LDs with varying operating current, and reduced device sizes. These factors lead to markedly increased manufacturing yields, higher device lifetimes, and superior performance compared to the conventional c-plane (polar) GaN technology.

Fundamental properties of semiconductor materials, such as the electronic band structure, band gap energies, dynamical and elastic properties, are directly related to lattice parameters. However, due to the very different strain conditions in bulk GaN grown by different methods, it is difficult to determine the intrinsic unstrained values, ${ }^{17}$ as reflected by a number of scattered values reported in the literature.

In this work, we present a thorough study of the structural and optical properties of state-of-the-art non-polar ammonothermal GaN substrates by high resolution x-ray diffraction (HR-XRD), Raman spectroscopy, and lowtemperature power-dependent cathodoluminescence (CL) spectroscopy. These techniques provide detailed and complementary information about the purity of the grown crystals, donor and acceptor states, residual doping, and mobility of carriers. Carrier concentration and effects of point defects are analyzed by longitudinal-optical phonon-plasmon coupling in Raman spectroscopy as well as by the saturation behavior of defect related luminescence in CL. The extraordinary crystalline quality is demonstrated by the low full width of half maximum values of Bragg reflections in HRXRD and Raman spectroscopy. Furthermore, XRD is utilized to determine the lattice parameters of bulk ammonothermal GaN.

\section{EXPERIMENTAL}

\section{A. Crystal growth and wafer preparation}

The ammonothermal method is a kind of solvothermal process that uses dissolution of polycrystalline III-nitride nutrient feedstock in supercritical ammonia under high pressure by utilizing a solubilizing agent or mineralizer. The dissolved nutrient is then transported to the region of crystallization, where it crystallizes on self-nucleated or pre-existing seed crystals. The chemical nature of the mineralizer employed determines the type of the ammonothermal approach. Mineralizers are generally divided into three groups: (i) basic mineralizers, which introduce $\mathrm{NH}_{2}{ }^{-}$ions to the solution; (ii) acidic, which introduce $\mathrm{NH}_{4}{ }^{+}$ions; and (iii) neutral, which do not introduce either of them. Dissolution of III-nitrides using potassium azide $\left(\mathrm{KN}_{3}\right)$ or potassium amide $\left(\mathrm{KNH}_{2}\right)$ ammonothermal-basic solutions ${ }^{18,19}$ has been suggested to occur through formation of soluble intermediate compounds, which subsequently decompose at higher temperature. In this study, we investigated m-plane substrates grown in ammonobasic environment at AMMONO S.A., where alkali metals or their amides $\left(\mathrm{LiNH}_{2}, \mathrm{NaNH}_{2}\right.$, or $\mathrm{KNH}_{2}$ ) are used as mineralizers. The details about the method can be found elsewhere. ${ }^{15}$ Substrates with dimensions of $9 \times 13 \mathrm{~mm}$ and thickness of $325 \mu \mathrm{m}$ were sliced from bulk GaN crystals. One side of the substrate was mechanically polished up to reaching an optical finishing while the back-side was roughly polished.

\section{B. Characterization methods}

For the high resolution x-ray diffraction experiment, a triple-axis setup is employed. The $\mathrm{x}$-rays emitted from a sealed copper anode are pre-collimated by a parabolic multilayer mirror and then pass a four-bounce Bartels monochromator using the 220 Bragg reflections of two highly perfect germanium channel cut crystals. The $\mathrm{x}$-ray beam is collimated down to the intrinsic Darwin width of the Ge 220 Bragg reflection of about $\Delta \theta_{\mathrm{D}}=11$ arc sec while the $\mathrm{Cu} \mathrm{K}_{\alpha 1}$ $(\lambda=1.54059 \AA)$ line is selected within a wavelength band of $\Delta \lambda / \lambda=1.28 \times 10^{-4}$. In front of a single channel scintillation detector, a two-bounce 220 germanium channel cut crystal analyser is mounted, which measures the direction $(2 \theta)$ of the diffracted beam with an accuracy of $11 \mathrm{arc} \mathrm{sec}$. The temperature during the measurements was fixed to $\mathrm{T}=(20$ $\pm 0.5)^{\circ} \mathrm{C}$ and the mechanical stability of the monochromator was checked at regular intervals by measuring the intensity of the primary beam. During the entire measurement period, we did not observe any long-term drift in the $x$-ray wavelength.

A detailed description of the technique can be found in Ref. 20. By using an analyser crystal both the rocking angle $\omega$ of the sample as well as the scattering angle $2 \theta$ can be used to evaluate the Bragg angles of various Bragg reflections. This eliminates any peak broadening caused by any microscopic (broadening by dislocations or micrograins) or macroscopic (e.g., bending) sample imperfections or any sample misalignment (e.g., non-excentricity) and enables a precise determination of the lattice parameters of single crystals with an accuracy of the order of $10^{-5}$.

Micro-Raman spectroscopy is performed in different geometries at room temperature using a laser excitation of $532 \mathrm{~nm}$ with a power of $50 \mathrm{~mW}$ and focusing the beam through a $100 \times$ microscope objective. CL measurements are performed with an FEI Quanta 200 ESEM with Gatan CF302 continuous flow liquid helium cold stage and an Ocean Optics QE65000 scientific-grade spectrometer (spectral range of $200-950 \mathrm{~nm}, 8 \mathrm{~nm}$ resolution). The excitation power dependent cathodoluminescence measurements are recorded at $\mathrm{T}=12 \mathrm{~K}, 10 \mathrm{kV}$ and with currents between $0.1 \mathrm{nA}$ and $100 \mathrm{nA}$ (with a spot size of approx. $10 \mathrm{~nm}$ at low currents).

\section{RESULTS AND DISCUSSION}

\section{A. Structural study}

The crystalline perfection of the non-polar (1-100) GaN was studied by means of various structural characterization methods. A variety of different Bragg reflections have been 

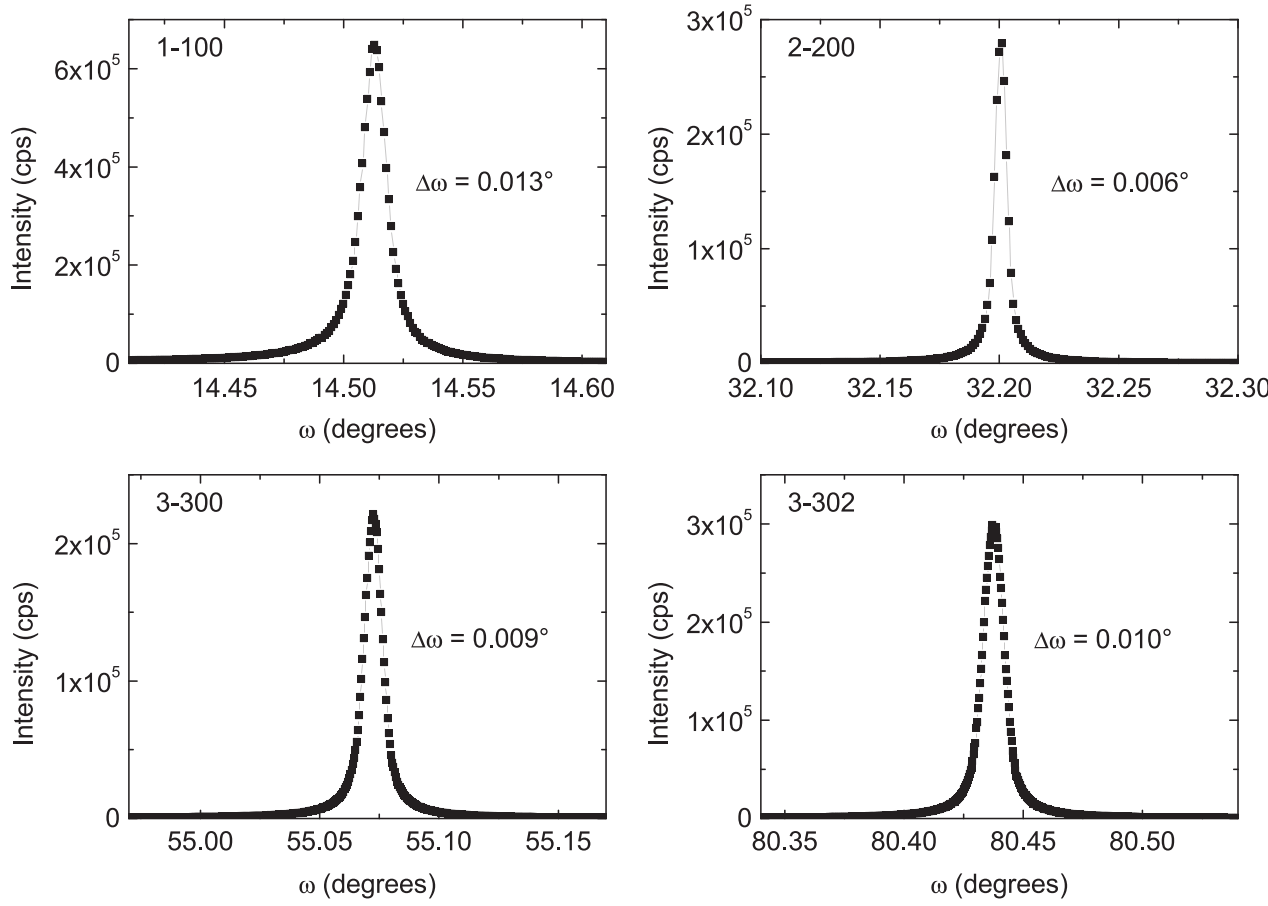

FIG. 1. Experimental X-ray rocking curves of m-plane ammonothermal $\mathrm{GaN}$. studied. Fig. 1 exemplarily illustrates the measured x-ray rocking curves $(\omega$-scan) at 4 different reflections. The crystals exhibited very narrow rocking curves with full widths at half maximum (FWHM) values close to the resolution limit of the diffractometer $\left(\Delta \omega=0.003^{\circ}\right)$, thus indicating very high crystalline perfection. These values are among the best ever reported in the literature for bulk GaN. Here, it should be mentioned that even a lower FWHM value of 15 arc sec for the symmetrical (1-100) reflection ${ }^{21}$ of m-plane ammonothermal substrates have been achieved. This difference could originate from the "optically polished" surface of the specimens used in this study, in which a damaged subsurface layer (about $500 \mathrm{~nm}$ in thickness) generated by mechanical polishing can be present.

A detailed knowledge of the lattice mismatch between the substrate and different epitaxial layers is essential in order to tune the strain state in coherently grown III-N epitaxial layers on GaN. The accurate evaluation of strains in layers grown on substrates again requires a precise knowledge of the substrate lattice parameters. Therefore, the $a$ and $c$ lattice parameters of the highly perfect ammonothermal GaN single crystals were determined with very high precision by employing a sophisticated HR-XRD technique, which is based on the modified Bond method. ${ }^{20}$ For this

TABLE I. Experimental values of lattice spacings $d_{h k l}$ for various Bragg reflections (hkl). Values in brackets are the errors in the last digits.

\begin{tabular}{llll}
\hline \hline $\mathrm{h}$ & $\mathrm{k}$ & 1 & $\mathrm{~d}_{\mathrm{hk} 1}(\AA)$ \\
\hline 1 & -1 & 0 & $2.76185(10)$ \\
2 & -2 & 0 & $1.38091(4)$ \\
3 & -3 & 0 & $0.92062(2)$ \\
2 & -2 & 3 & $1.07886(2)$ \\
2 & -2 & 2 & $1.21881(4)$ \\
2 & -2 & 1 & $1.33440(4)$ \\
\hline \hline
\end{tabular}

purpose, a variety of different independent Bragg reflexes (hkl) has been investigated, and the corresponding lattice spacings, $\mathrm{d}_{\mathrm{hkl}}$, are displayed in Table $\mathrm{I}$.

The $a$ and $c$ lattice parameters can be determined from the $\mathrm{d}_{\mathrm{hkl}}$-values in Table I by using the following relationship for hexagonal crystals:

$$
\frac{1}{d_{h k l}}=\sqrt{\frac{4\left(h^{2}+k^{2}+h k\right)}{3 a^{2}}+\frac{l^{2}}{c^{2}}} .
$$

The lattice parameters were determined using an iterative refinement procedure as described in Ref. 20. The results obtained are summarized in Table II. For comparison, literature values for $a$ and $c$ lattice parameters of HVPE and HPSG GaN materials ${ }^{12}$ are also listed.

In principle, the lattice parameters of $\mathrm{GaN}$ could be affected by incorporation of impurities or native point defects (e.g., vacancies). At the concentrations typical for ammonothermal material, these defects are, however, expected to have a minor influence on the lattice parameters. Varying internal strain caused by structural defects like dislocations, on the contrary, could have a significant impact. At sufficiently high dislocation densities, the inhomogeneous strain field around individual dislocations leads to a broadening of the x-ray rocking curves, which depends on the

TABLE II. Experimental $a$ and $c$ lattice parameters for ammonothermal, HPSG, and HVPE GaN. Values in brackets are the errors in the last digits.

\begin{tabular}{lcc}
\hline \hline Material & $\mathrm{a}(\AA)$ & $\mathrm{c}(\AA)$ \\
\hline Ammonothermal & $3.18908(10)$ & $5.18517(10)$ \\
HVPE $^{11}$ & $3.1880(20)$ & $5.1868(15)$ \\
HVPE (Sumitomo) & $3.1892(2)$ & $5.18542(2)$ \\
HPSG (Unipress) & $3.1881-3.1890$ & \\
\hline \hline
\end{tabular}


relative orientation of the Burger's vector with respect to the scattering vector. If the dislocation density exceeds a certain threshold, the strain fields of adjacent dislocations may overlap which may cause a change of lattice parameters. For our ammonothermal samples, the x-ray rocking curve width is of the same order of magnitude of the experimental resolution. This implies a comparatively low DD, i.e., the distance between adjacent dislocations is sufficiently large so that the strain fields between neighbouring dislocations cannot overlap. As a result of missing overlapping, the mean lattice parameters, as measured by XRD, remain unchanged. It may be concluded that in this case, the few residual dislocations have a negligible impact on the (mean) lattice parameters in our sample.

In contrast, larger $\mathrm{x}$-ray rocking curve widths were found for homoepitaxial HVPE and metalorganic chemical vapor deposition (MOCVD) samples with much larger dislocation densities. ${ }^{22}$ Here, we expect a remarkable impact of dislocations on the lattice parameters.

High-pressure solution grown $\mathrm{GaN}$ bulk crystals exhibit a lattice parameter $a$ between 3.1881 and $3.1890 \AA$ A. This material has been shown to be unintentionally doped with oxygen; it indeed exhibits a $n$-type conductivity consistent with a donor concentration around $10^{20} \mathrm{~cm}^{-3}$. The effects on the lattice parameters due to incorporation of oxygen impurities in $\mathrm{GaN}$ were evaluated by Van de Walle ${ }^{23}$ using firstprinciples pseudopotential-density-functional calculations. It was estimated that such an oxygen concentration will lead to an expansion of the lattice and will increase $a$ by $0.0008 \AA$. We suggest that the lattice parameters measured on ammonothermal GaN in the present study can be used as standard parameters for stress-free $\mathrm{GaN}$.

\section{B. Optical properties}

The micro-Raman spectra recorded in backscattering configuration are shown in Fig. 2 for parallel and crossed polarization in the case of c-plane and m-plane surfaces. The Raman modes provide, in contrast to the XRD measurements, information on the local short range ordering of the atoms in the crystal, on the strain state of the lattice, as well as on the electric properties of the material. According to the

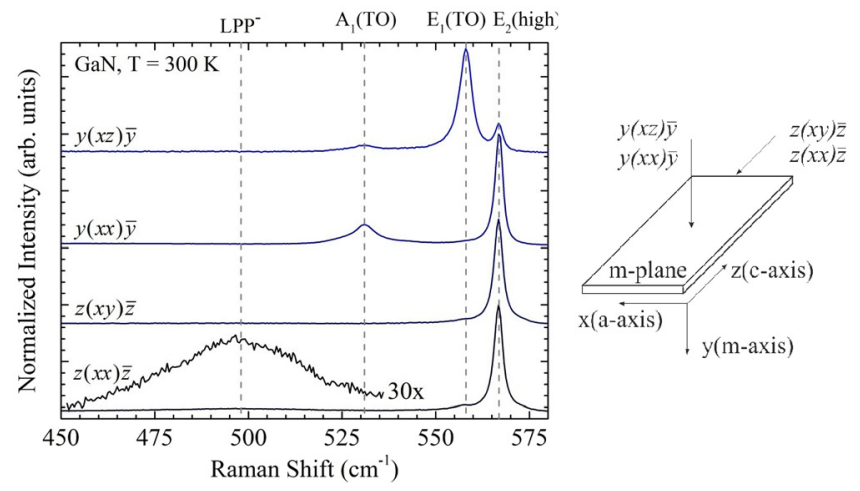

FIG. 2. $\mu$-Raman spectra for different configurations of the incident and scattered light and its polarization in the range of the $\mathrm{LPP}^{-}, \mathrm{A}_{1}(\mathrm{TO})$, $\mathrm{E}_{1}(\mathrm{TO})$, and $\mathrm{E}_{2}(\mathrm{high})$ modes.
Raman selection rules for wurtzite materials, the $A_{1}(T O)$, $\mathrm{E}_{1}(\mathrm{TO}), \mathrm{E}_{2}$ (high), and $\mathrm{E}_{1}(\mathrm{LO})$ modes can be observed in the different orientations. Instead of the commonly observed $\mathrm{A}_{1}(\mathrm{LO})$ mode, coupled longitudinal-optical phonon-plasmon modes (LPP) were observed. ${ }^{24}$ The energetic position of the non-polar $\mathrm{E}_{2}$ (high) mode at $566.6(3) \mathrm{cm}^{-1}$ indicates a strainfree (relaxed) crystal. ${ }^{25-27}$ The very narrow full width at half maximum of $\Gamma=2.8 \mathrm{~cm}^{-1}$ further proves the excellent structural quality in agreement with the XRD data. This width equals the narrowest reported line width in GaN substrates. ${ }^{24}$ This usually indicates exclusively homogeneous broadening. The line width is mainly governed by the phonon lifetime whereas broadening due to anharmonic decay and defect scattering is negligible. The positions of the Raman modes and their line width are listed in Table III. The position of the observed $\mathrm{LPP}^{-}$mode indicates a free carrier concentration in the range of $2 \times 10^{19} \mathrm{~cm}^{-3} \cdot 24,28,29$

Fig. 3(a) shows the low-temperature CL spectra, which were recorded for different excitation power densities at a temperature of $10 \mathrm{~K}$. The prominent features in the spectra are the bound exciton emission $(\mathrm{BX})$ at $3.45 \mathrm{eV}$, the donoracceptor-pair (DAP) luminescence at $3.29 \mathrm{eV}$, and two broad bands in the blue and green spectral regions. The luminescence at $3.20 \mathrm{eV}$ with a distance of approximately $90 \mathrm{meV}$ to the DAP is the first LO phonon sideband of the DAP zerophonon line. The spectra were normalized for the excitonic luminescence $(\mathrm{BX})$. In addition, a high resolution measurement of the excitonic luminescence is depicted showing only one distinct bound exciton.

With increasing excitation power, a second replica (DAP2LO) positioned at $3.11 \mathrm{eV}$ becomes visible. Apparently neither the DAP nor the BX emission exhibits a pronounced energy shift as function of the excitation power. In the case of the bound exciton emission, this can be explained by the compensating effects of bandgap renormalization and carrier screening in $\mathrm{GaN}$ as reported by Reynolds et $a l .{ }^{30-32}$ The absence of the typical blue shift of the DAP with increasing excitation power due to a reduced mean distance of ionized donors and acceptors shows that no potential fluctuations within the band structure occur. ${ }^{33}$ In comparison to the BX emission, the DAP as well as the defect related blue and green luminescence bands show a reduced intensity increase with increasing excitation power, indicating saturation of those processes in the high excitation regime (cf. Fig. 3(b)).

The presence of the BL peak may be associated with the slight compensation of non-intentional donors by acceptors in this sample. These transitions are also common in other

TABLE III. Peak positions and full width at the half maximum values for the observed Raman modes at $300 \mathrm{~K}$. Values in brackets are the errors in the last digit.

\begin{tabular}{lcc}
\hline \hline & Raman shift $\left(\mathrm{cm}^{-1}\right)$ & FWHM $\left(\mathrm{cm}^{-1}\right)$ \\
\hline LPP & $497.5(2)$ & $61(8)$ \\
$\mathrm{A}_{1}(\mathrm{TO})$ & $531.0(3)$ & $14.7(2)$ \\
$\mathrm{E}_{1}(\mathrm{TO})$ & $558.0(3)$ & $12.1(2)$ \\
$\mathrm{E}_{2}$ (high) & $566.6(3)$ & $2.6(1)$ \\
\hline \hline
\end{tabular}


$2.45 \mathrm{eV} \quad 2.88 \mathrm{eV} \quad 3.20 \mathrm{eV} \quad 3.29 \mathrm{eV} \quad 3.46 \mathrm{eV}$

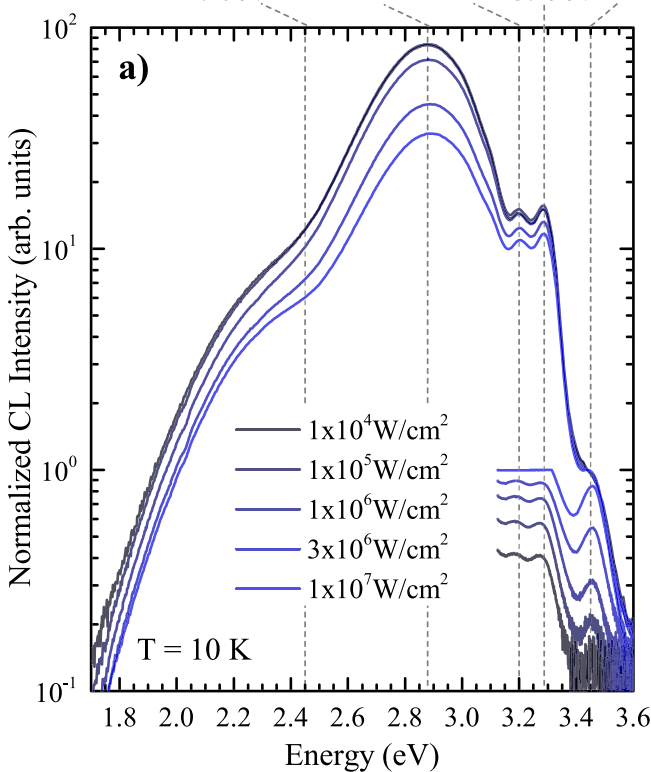

FIG. 3. Cathodoluminescence spectra for excitation power densities between $10 \mathrm{~kW} / \mathrm{cm}^{2}$ and $10 \mathrm{MW} / \mathrm{cm}^{2}$ at $\mathrm{T}=10 \mathrm{~K}$ between $1.7 \mathrm{eV}$ and $3.6 \mathrm{eV}$ and high resolution spectra of the near band-edge luminescence (a). Peak intensities as function of excitation power density in a double logarithmic scale (b). wurtzite wide band gap semiconductors, such as, e.g., $\mathrm{ZnO}$, where optical emission lines caused by basal plane stacking faults $^{34}$ and excitons bound to extended structural defects ${ }^{35}$ were recently identified.

The observed DAP luminescence in the samples is likely linked to the incorporation of contaminants from the ammonothermal growth process. Together with other point defects, these contaminants may be responsible for the observed blue and green luminescence bands. ${ }^{36}$ However, for substrate applications the very high crystalline perfection in terms of low DDs is of paramount importance and a high purity of the overgrown device heterostructures can be achieved employing MOCVD or MBE growth methods enabling very low impurity incorporation levels (such as oxygen and silicon).

\section{CONCLUSION}

The structural and optical properties of state-of-the-art m-plane bulk GaN grown by the ammonothermal process were investigated. The structural analysis by HR-XRD and Raman spectroscopy proves the excellent crystalline quality of the material. The lattice parameters of strain-free GaN were accurately determined by XRD. From the very narrow Bragg reflexes, it can be argued that this material has a very good long range ordering, whereas the narrow line width of the $\mathrm{E}_{2}$ (high) Raman mode confirms the very good short range ordering. The position of the $\mathrm{E}_{2}$ (high) mode indicates a relaxed lattice. The extremely high curvature radius, together with the very high crystalline perfection, proves the great potential of such ammonothermal GaN crystals as substrates for manufacturing of $\mathrm{GaN}$-based devices.

${ }^{1}$ F. A. Ponce and D. P. Bour, Nature 386, 351 (1997).

${ }^{2}$ S. Nakamura, Science 281, 956 (1998).

${ }^{3}$ B. Beaumont, Ph. Vennéguès, and P. Gibart, Phys. Status Solidi B 227, 1 (2001).

${ }^{4}$ D. Gogova, A. Kasic, H. Larsson, C. Hemmingsson, B. Monemar, F. Toumisto, K. Saarinen, L. Dobos, B. Pécs, P. Gibart, and B. Beaumont, J. Appl. Phys. 96, 799 (2004).
${ }^{5}$ T. S. Zheleva, S. A. Smith, D. B. Thomson, K. J. Linthicum, P. Rajagopal, and R. F. Davis, J. Electron. Mat. 28(4), L5 (1999).

${ }^{6}$ Technology of Gallium Nitride Crystal Growth, edited by D. Ehrentraut, E. Meissner, and M. Bockowski (Springer Verlag, Heidelberg, 2010).

${ }^{7}$ A. Denis, G. Goglio, and G. Demazeau, Mater. Sci. Eng. R. 50, 167 (2006).

${ }^{8}$ Y. Mori, Y. Kitaoka, M. Imade, F. Kawamura, N. Miyoshi, M. Yoshimura, and T. Sasaki, Phys. Status Solidi A 207(6), 1283 (2010).

${ }^{9}$ F. Kawamura, M. Tanpo, N. Miyoshi, M. Imade, M. Yoshimura, Y. Mori, Y. Kitaoka, and T. Sasaki, J. Cryst. Growth 311, 3019 (2009).

${ }^{10}$ I. Grzegory, M. Boćkowski, P. Strąk, S. Krukowski, and S. Porowski, J. Cryst. Growth 312(18), 2593 (2010).

${ }^{11}$ D. Gogova, D. Siche, A. Kwasniewski, M. Schmidbauer, R. Fornari, C. Hemmingsson, R. Yakimova, and B. Monemar, Phys. Status Solidi C 7(7-8), 1756 (2010).

${ }^{12}$ See www.sumitomo.jp for HVPE GaN crystals.

${ }^{13}$ See www.kymatech.com for HVPE GaN crystals.

${ }^{14}$ D. Gogova, A. Kasic, H. Larsson, B. Pécz, R. Yakimova, B. Magnusson, B. Monemar, F. Tuomisto, K. Saarinen, C. Miskys, M. Stutzmann, C. Bundesmann, and M. Schubert, Jpn. J. Appl. Phys., Part 1 43, 1264 (2004).

${ }^{15}$ R. Dwiliński, R. Doradziński, J. Garczyński, L. Sierzputowski, R. Kucharski, M. Zając, M. Rudziński, R. Kudrawiec, J. Serafińczuk, and W. Strupiński, J. Cryst. Growth 312(18), 2499 (2010).

${ }^{16}$ A. E. Romanov, T. J. Baker, S. Nakamura, and J. S. Speck, J. Appl. Phys. 100, 023522 (2006).

${ }^{17}$ J.-M. Wagner and F. Bechstedt, Phys. Rev. B 66, 115202 (2002).

${ }^{18}$ R. Dwilinski, R. Doradzinski, J. Garczynski, L. Sierzputowski, J. M. Baranowski, and M. Kaminska, Diamond Relat. Mater. 7, 1348 (1998).

${ }^{19} \mathrm{~B}$. Wang and M. Callahan, J. Cryst. Growth 291, 455 (2006).

${ }^{20}$ M. Schmidbauer, J. Schwarzkopf, and A. Kwasniewski, Acta Cryst. B 68, 8 (2012).

${ }^{21}$ R. Kucharski, M. Rudziński, M. Zając, R. Doradziński, J. Garczyński, L. Sierzputowski, R. Kudrawiec, J. Serafińczuk, W. Strupiński, and R. Dwiliński, Appl. Phys. Lett. 95, 131119 (2009).

${ }^{22} \mathrm{H}$. Morkoç, Handbook of Nitride Semiconductors and Devices, GaN-based Optical and Electronic Devices, (Wiley-VCH Verlag GmbH, 2008), Vol. 3.

${ }^{23}$ C. G. Van de Walle, Phys. Rev. B 68, 165209 (2003).

${ }^{24}$ A. Kaschner, H. Siegle, A. Hoffmann, C. Thomsen, U. Birkle, S. Einfeldt, and D. Hommel, MRS Proc. 537, G3.57 (1998).

${ }^{25}$ U. Haboeck, H. Siegle, A. Hoffmann, and C. Thomsen, Phys. Status Solidi C 0(6), 1710 (2003)

${ }^{26}$ G. Callsen, M. R. Wagner, T. Kure, J. S. Reparaz, M. Bügler, J. Brunnmeier, C. Nenstiel, M. Hoffmann, J. Tweedie, Z. Bryan, S. Aygun, R. Kirste, R. Collazo, Z. Sitar, and A. Hoffmann, Phys. Rev. B 86, 075207 (2012).

${ }^{27}$ R. Kirste, Ph.D. dissertation, TU, Berlin, 2012. 
${ }^{28}$ M. Klose, R. Dassow, M. Gross, and H. Schröder, J. Cryst. Growth 189-190, 666 (1998).

${ }^{29}$ S. Fritze, A. Dadgar, H. Witte, M. Bügler, A. Rohrbeck, J. Bläsing, A. Hoffmann, and A. Krost, Appl. Phys. Lett. 100, 122104 (2012).

${ }^{30}$ D. C. Reynolds, C. W. Litton, T. C. Collins, J. E. Hoelscher, and J. Nause, Appl. Phys. Lett. 88, 141919 (2006).

${ }^{31}$ E. Oh, H. Park, and Y. Park, Appl. Phys. Lett. 72, 70 (1998).

${ }^{32}$ B. I. Shklovskii and A. L. Efros, Electronic Properties of Doped Semiconductors (Springer, Berlin, 1984), p. 52.

${ }^{33}$ S. Lautenschlaeger, S. Eisermann, G. Haas, E. A. Zolnowski, M. N. Hofmann, A. Laufer, M. Pinnisch, B. K. Meyer, M. R. Wagner, J. S.
Reparaz, G. Callsen, A. Hoffmann, A. Chernikov, S. Chatterjee, V. Bornwasser, and M. Koch, Phys. Rev. B 85, 235204 (2012).

${ }^{34}$ M. Schirra, R. Schneider, A. Reiser, G. M. Prinz, M. Feneberg, J. Biskupek, U. Kaiser, C. E. Krill, K. Thonke, and R. Sauer, Phys. Rev. B 77, 125215 (2008).

${ }^{35}$ M. R. Wagner, G. Callsen, J. S. Reparaz, J.-H. Schulze, R. Kirste, M. Cobet, I. A. Ostapenko, S. Rodt, C. Nenstiel, M. Kaiser, A. Hoffmann, A. V. Rodina, M. R. Phillips, S. Lautenschläger, S. Eisermann, and B. K. Meyer, Phys. Rev. B 84, 035313 (2011).

${ }^{36}$ M. A. Reshchikov and H. Morkoç, J. Appl. Phys. 97, 061301 (2005). 